STRUCTURAL BIOLOGY

ISSN 2059-7983

Keywords: book reviews; structural biology.

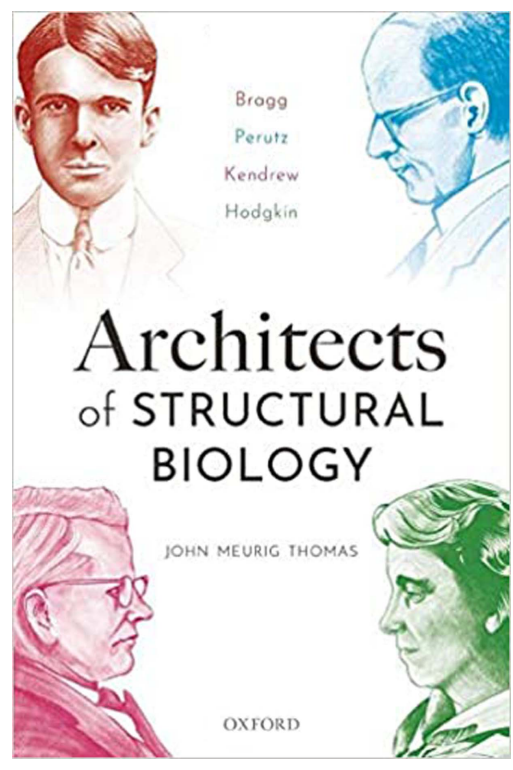

(C) 2021 International Union of Crystallography

\section{Architects of Structural Biology: Bragg, Perutz, Kendrew, Hodgkin. By John Meurig Thomas. Oxford University Press, 2020. Pp. 320. GBP 35 (hardback), ISBN 9780198854500}

\author{
Anders Liljas* \\ Lund University, Åkeröv. 26, SE-793 33 Leksand, Sweden. *Correspondence e-mail: anders.liljas@biochemistry.lu.se
}

The early part of the 20th century was a highly exciting scientific period in many respects, one of these being that it gave birth to a new science, structural biology. This field has continued to have a great impact on biology in general since methods were developed to see the atomic arrangements of the molecules of life, nucleic acids, proteins, lipids and carbohydrates. A recent book describes these developments from the valuable and closeup perspective of Sir John Meurig Thomas. It is an excellent book for all interested in the history of science.

The book deals with how it all began with the discovery in 1912 by Max von Laue, in Munich, that crystals diffracted X-rays. This provided not only the understanding that $\mathrm{X}$-rays were electromagnetic radiation of short wavelength but also that crystals were well organized objects. This led father and son William Henry and William Lawrence Bragg, in Leeds and Cambridge, to realise that such experiments could lead to the structure of crystals. In the same year the son, William Laurence Bragg (WLB), had already determined the structure of some alkali halides and other simple compounds. It was obvious that the method could be further developed to determine the structures of more complex structures. The field took a great leap when John Desmond Bernal and Dorothy Crowfoot (later Hodgkin) took the first diffraction pictures of a protein crystal (pepsin). Max Perutz then began studies in Cambridge with the aim to determine the structure of haemoglobin. A strong supporter of this development was WLB, who by now was Professor of the Cavendish Laboratory. Since it seemed strange to perform biological work in a physics laboratory, he made a shed in the parking lot available to Perutz and his growing number of co-workers. The work in the shed, or the 'hut', was transferred to the newly created Medical Research Council Laboratory for Molecular Biology (LMB) at the end of the 1960s.

Parallel to the work on developing methods to determine the structures of proteins and nucleic acids, Perutz, WLB, Francis Crick and John Kendrew (the latter two being Perutz's graduate students), tried to generate models of the structure of proteins. Early work was also done by Maurice L. Huggins. Crystal structures of amino acids and basic information from the X-ray diffraction patterns of proteins provided constraints. The Cambridge workers were beaten to discovering the correct structures by Pauling, Corey and Branson at Caltech, who had not only realised that the peptide group is planar but also that the helical structure did not need to have an integer number of residues in each turn. They proposed both the $\alpha$-helix and $\beta$-structures.

In addition to Francis Crick's contributions to the protein work, he and Jim Watson focused on the structure of DNA, the genetic material of all organisms. However, the book only gives limited insight into this exciting field as the focus of the book is on proteins. Thus, the breakthrough on the structures of myoglobin in 1959 and haemoglobin in 1965 by Kendrew, Perutz and their co-workers are well covered. Here the observations of $\alpha$-helices could be enjoyed in multiple examples. Parts of the physiological insights from the structural results are also discussed. The next step in the arena of proteins was the first structure of an enzyme, lysozyme, in 1965. This was owing to David Phillips and his co-workers working at the Davy-Faraday Research Laboratory at the Royal Institution in London directed by WLB. Here, not only was the first $\beta$-structure observed but also the binding of substrates led to discussions of the catalytic mechanism.

Yet another laboratory in the UK is highlighted. This is Dorothy Crowfoot Hodgkin's laboratory at Oxford University. She had earlier determined structures of smaller 
compounds like penicillin and vitamin B12, both of which provided almost unbelievable surprises. However, the main thrust was on the structure of the hormone insulin, which was solved in 1969.

The author of the book, who very recently passed away, was geographically close to most of these events and a friend of the majority of the persons involved. This gives an unusually detailed insight into the steps of the process and the personalities involved. At the same time his scientific field, solid state physics, was different from the focus of the book. He was a professor at Cambridge University and had been a director of the Royal Institution, London, like father and son Bragg. In addition, he was a fellow of Peterhouse college, the oldest college at Cambridge University, like many of the colleagues he is writing about. His insight due to the close connections to the main people in the book gives a valuable perspective on how it was possible for an activity that began in a shed at a parking lot to develop into a world-leading laboratory (LMB), where former and present members have won twenty-three Nobel Prizes. The secrets behind the successes were due to the leaders, primarily William Laurence Bragg and Max Perutz, and the traditions they generated: a happy and friendly atmosphere in the laboratory as well as free exchange of ideas with a general attitude that the science jointly produced by the laboratory will benefit all.

The author also makes some remarkable observations, among which are that several key persons, including Nobel Prize winners, had very modest publication records. With such $\mathrm{H}$-indices they would have had a difficult time to be appointed even as lecturers at a university today. This may illustrate a serious problem in recruitment of today, but also the wisdom of the granting agencies of the past to recognise personal qualities and brave attempts to break new ground. 